\title{
Potential of Using TPM to Increase the Efficiency of Production Processes
}

\author{
Vladimíra SCHINDLEROVÁ, Ivana ŠAJDLEROVÁ, Václav MICHALČíK, Jan NEVIMA, Lucie KREJČí
}

\begin{abstract}
The goal of the submitted paper is to implement the principles of TPM and to achieve almost $100 \%$ usability of machines, when there will be no failures and unwanted incidents. The effectiveness of implementing the TPM principles has been experimentally verified in an engineering company. Workplaces for the assembly of rails on Unimatic lines were chosen as a pilot workplace. Prior to the implementation of the TPM, analyses of technical downtime and unplanned shutdowns of the manufacturing devices due to failures, unplanned repairs and maintenance were carried out. The resulting analysis concentrated mainly on two main variables - total cumulative technical downtime at individual workplaces and frequency of occurrence of failures in individual sections of the workplaces. The presented approach and the results obtained underline the importance of applying the TPM principles in practice and their indisputable contribution to the ability to increase business performance. The TPM's progressive maintenance management system represents a prerequisite for the reduction of production costs and losses resulting from unscheduled failures now and in the future.
\end{abstract}

Keywords: maintenance; management system; OEE; technical downtime; TPM

\section{INTRODUCTION}

Although the world economy is currently on the rise, streamlining of the production processes with the focus on elimination of the waste times, which may be caused due to malfunctions or abnormalities in manufacturing devices, is a constant requirement [2]. Some foreign surveys show that the maintenance and repair costs (including warehousing costs and tied capital here) may account for up to $25 \%$ of the company's turnover and $15 \%$ to $40 \%$ of the total operating costs $[3,19]$. The maintenance process shares a significant part of the operating costs in an industrial organization $[15,23,24]$. Bevilacqua and Braglia stated that in the United States, the estimated maintenance costs increased from \$ 200 billion in 1979 to $\$ 600$ billion in 1989 [1]. It is necessary to find a mechanism in the decision-making process to change the approach to maintenance area management. Nowadays, new maintenance systems are not being developed, but it is more likely about the way of implementing them into businesses because each system is unique. Thus, the objective is to find a tool for the decision-making process to prove the benefits or inappropriateness of implementing a new maintenance management system [10]. The TPM principles have been elaborated in a number of studies, however, there is a lack of experience in their practical implementation. TPM is an approach specific to its versatility and, paradoxically, at the same time to a great individuality in its implementation itself [13].

\section{PRINCIPLE OF PERMANENT MAINTENANCE IMPROVEMENT}

In today's world, Lean Manufacturing represents a methodology used in all branches. Studies have shown that the application of Lean Manufacturing principles still proceeds in a fragmented way, often without logical continuity [11]. The principle of continuous improvement is one of the essential approaches to manufacturing itself, but it necessitates the application of a number of its tools (Fig. 1), which are quite many. Each enterprise has to determine whether it is advantageous to use these tools in its processes, or to what extent, especially for reasons of the cost-benefit balance that each of these implementations of the instruments entails [6]. Total Productive Maintenance (TPM) as such is considered one of the most significant tools used in lean manufacturing [20]. Currently, the TPM is also implemented, or is in the implementation phase, in a number of automotive and nonautomotive businesses. TPM can be used as a systematic means to avoid losses and increase the productivity of manufacturing devices. It is important to implement the TPM principles strategically on the basis of analyses of the causes of equipment failure and the proposed targeted improvement [7].

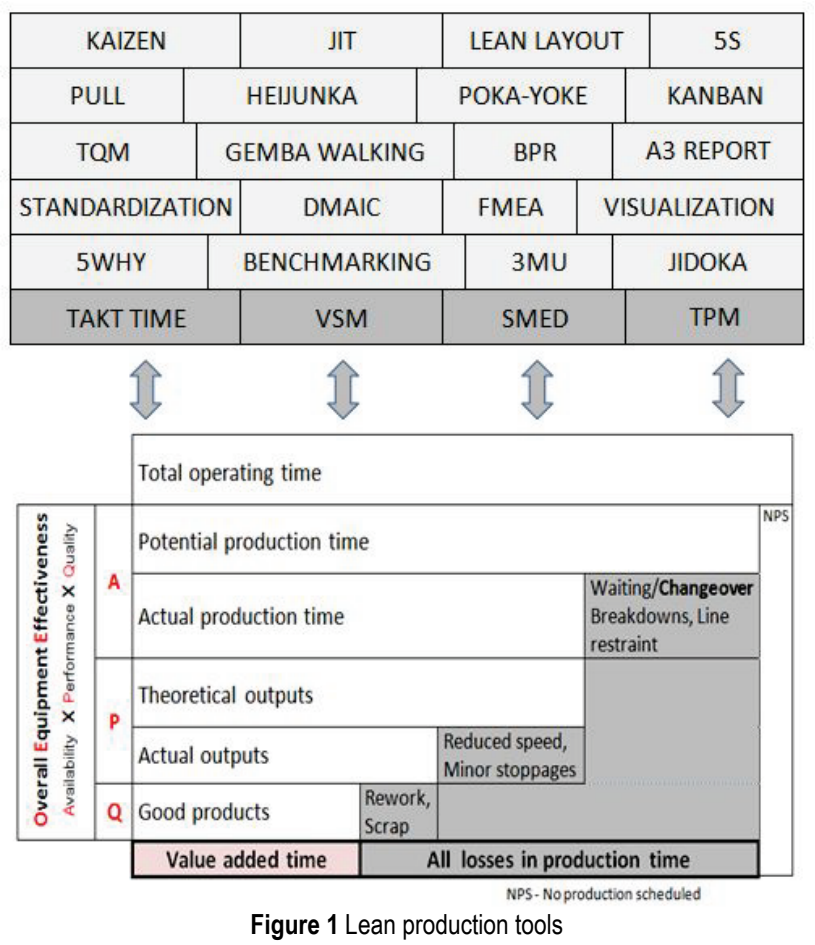

\section{PRINCIPLE OF TOTAL PRODUCTIVE MAINTENANCE}

Maintenance can be defined as processes and activities which ensure the operability of the manufacturing devices, or alternatively eliminate the malfunctions and their consequences. The maintenance claims grow in 
accordance with the sharp increase in complexity of devices and their automation [14, 17]. Over the past decades, the approach to the care security of manufacturing devices has undergone significant changes (Fig. 2). This development was influenced mainly by the fierce development of the technical equipment of the companies and, last but not least, by the pressure to rationalize the process and save the costs $[10,18,21]$. Each of the above mentioned maintenance management systems includes more or less the previous level, as the TPM contains the basic philosophy of all these previous maintenance approaches [4].

\begin{tabular}{|c|c|c|c|c|c|}
\hline Generation & $1^{\text {st }}$ generation & \multicolumn{2}{|c|}{$2^{\text {nd }}$ generation } & \multicolumn{2}{|c|}{$3^{\text {rd }}$ generation } \\
\hline $\begin{array}{c}\text { Development } \\
\text { Stage }\end{array}$ & Grade 1 & Grade 2 & Grade 3 & Grade 4 & Grade 5 \\
\hline $\begin{array}{c}\text { Maintenance } \\
\text { System }\end{array}$ & Break-down & Preventive & Productive & Total Productive & $\begin{array}{c}\text { Reliability } \\
\text { Centred }\end{array}$ \\
\hline Abbreviation & BM & PM1 & PM2 & TPM & RCM \\
\hline Time Period & $\begin{array}{c}1930 \text { s to World } \\
\text { War II }\end{array}$ & $\begin{array}{c}50 \text { to } 80 \text { s of } \\
\text { the 20th } \\
\text { century }\end{array}$ & $\begin{array}{c}70 \text { to } 90 \text { s of } \\
\text { the 20th } \\
\text { century }\end{array}$ & $\begin{array}{c}80 \text { of the 20th } \\
\text { century to the } \\
\text { beginning of the } 21^{\text {tht }} \\
\text { century }\end{array}$ & $\begin{array}{c}\text { The beginning } \\
\text { of the 215t } \\
\text { century to the } \\
\text { first decade }\end{array}$ \\
\hline
\end{tabular}

Figure 2 Development of the maintenance systems

The base of the TPM is represented with a preventive and proactive approach to maintenance throughout the enterprise. In order to achieve the TPM goals and maximum productivity [5], it is necessary to look at the manufacturing enterprise as a whole and not just as part of the enterprise where the production itself takes place [9] or [16]. TPM becomes not just a maintenance philosophy, it is a part of the corporate strategy and philosophy [22]. TPM aims to achieve the following goals:

- no unplanned failures and malfunctions,

- no defective products,

- no accidents.

The TPM achieves the above stated goals using the basic 8 pillars which serve as the base for the TPM maintenance system philosophy, with one of the essential ideas being to increase the productivity by engaging all staff in the proactive maintenance [12]. The basic pillars are:

- Autonomous maintenance - machine operators perform the state monitoring on their own machinery equipment and work environment.

- Process and Machine Improvements - managers collect the data from operators and the work environment and then prioritize preventive maintenance and possible machine and process improvement.

- $\quad$ Preventive / planned maintenance - machine operators and managers share tasks and timetables to ensure preventive maintenance.

- Timely ensuring of new equipment - managers predict and plan relative lifespan of used machinery.

- Process Quality Management - shared responsibility for production and maintenance, encouraging ideas to improve the quality in any area of the manufacturing enterprise.

- Education and training - continuous improvement involves machine operators and other employees owing to education and training which improves morale and overall efficiency.

- Safety and Sustained Success - priority is given to security throughout the enterprise which positively affects the successful TPM.
- Administrative work - managers prefer data obtained from previous pillars and share their results with senior executives and working departments. This also means the introduction of the TPM principles within the administration [5].

Maintenance itself is perceived by enterprises as a process that generates no profit, and therefore the TPM is considered the most difficult tool of lean manufacturing. The implementation can take many years, yet the result is greatly paid off both in production and motivation and employee morale.

\section{EXAMPLE OF IMPLEMENTATION OF TPM PRINCIPLES INTO MAINTENANCE}

Practice in the field of maintenance implementation in Czech companies, compared with the theoretical possibilities developed in the framework of maintenance management systems, is significantly different.

A survey in several engineering companies has shown that most companies not only do not carry out the necessary diagnostics of manufacturing equipment as part of the maintenance and are therefore unable to identify germs of upcoming failures and accidents but do not even create a sufficient item plan of periodic preventive maintenance and do not respect the timetable of preventive maintenance by age of the production equipment. Moreover, the system of continuous training of operators for sensitive handling of the production equipment and their involvement into the system of basic subjective diagnostics was not available in any of the companies tested (Fig. 3) [10].

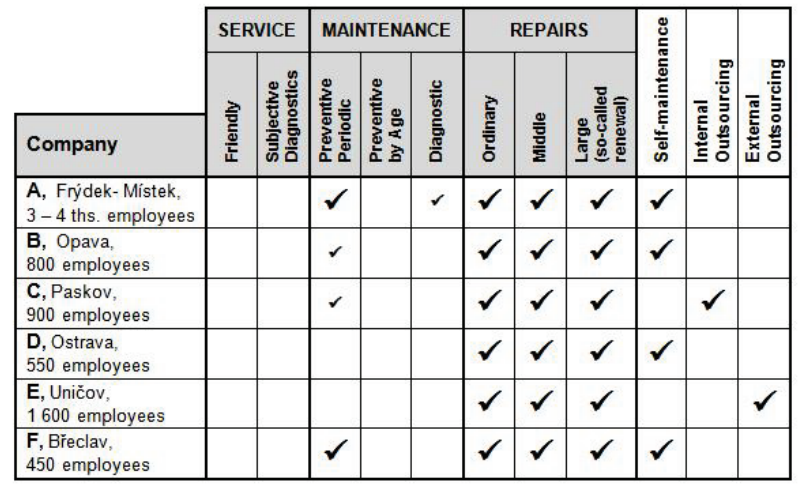

Figure 3 Maintenance management system in selected companies

Therefore, most companies do not deliberately deal with prevention or diagnostics and remain with lower levels of maintenance management systems (PM2, PM1 and BM). The high cost of repairs and accidents then enormously burden their economic performance, prevent the power from changing the system, and get companies into a situation where it is difficult to find a way out (a vicious circle). Convincing the management that a change in maintenance management will lead to cost savings is a top priority [10].

The effectiveness of implementing the TPM principles has been experimentally verified in an engineering company. Workplaces for the assembly of rails on Unimatic lines were chosen as a pilot workplace. Unimatic 1 assembly workstation comprises 3 workplaces known as $A P 1, A P 2$ and $A P 3$. These individual workplaces also have their own stations. The $A P 1$ workstation consists of one 
station only, $A P 2$ has a total of 13 stations, and AP3 comprises 4 stations. Unimatic 1 and Unimatic 2 are similar devices. The Unimatic 3 / PL6 asembly workstation is composed of 2 cells (Zell) which are tied together. Cell 1 (Zelle $1=Z 1)$ has 7 stations and cell 2 (Zelle $2=Z 2$ ) consists of 6 stations, where the conveyor is connected to the last station of cell 2 [8].

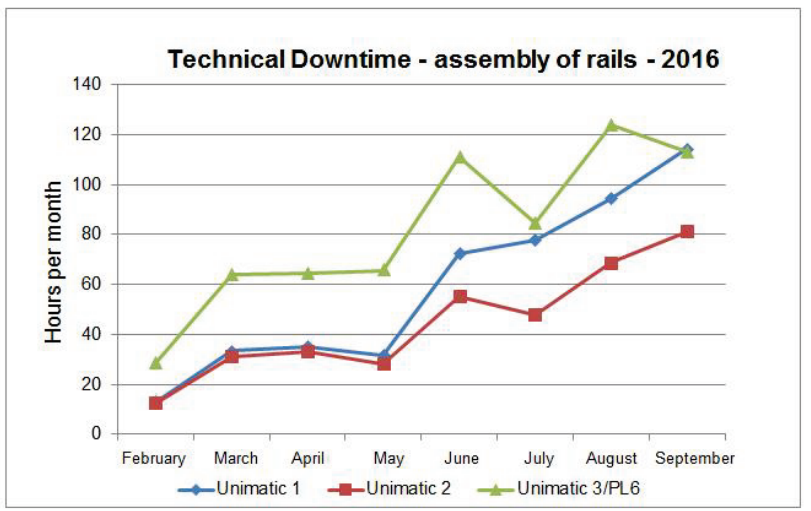

Figure 4 Analysis of the development of technical downtime at individual assembly sites
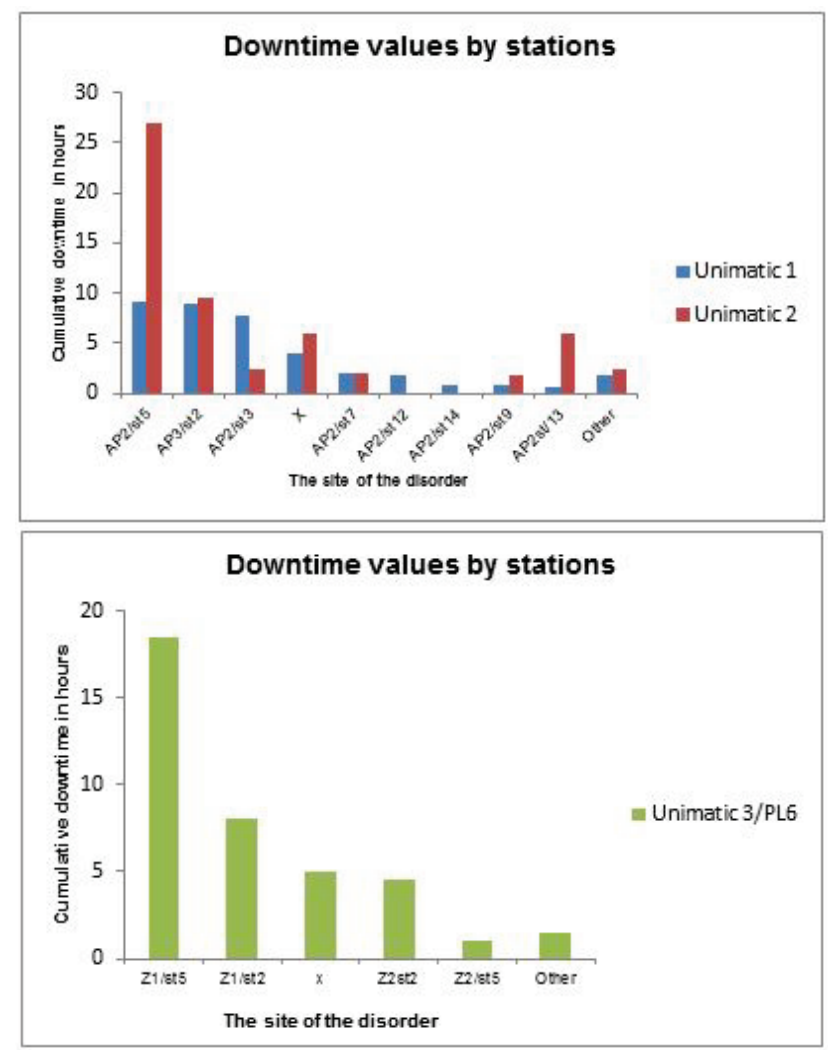

Figure 5 Paret analysis of cumulative downtime for workplaces Unimatic 1, Unimatic 2, Unimatic 3 / PL6

Prior to the implementation of the TPM, analyses of technical downtime and unplanned shutdowns of the manufacturing devices due to failures, unplanned repairs and maintenance during the period from February to September 2016 were carried out. The jump in technical downtime was caused mainly by a change in the number of shifts, with 15 shifts per month in the first four months and 18 shifts per month in the following period. Substantial effect on technical downtime was also the result of the fluctuation of workers mainly in the second half of the year (Fig. 4).

The results of the analysis showed that the greatest technical downtime was at the Unimatic 3 / PL6 and Unimatic 1 workplaces. Based on these results, detailed monitoring and data collecting at individual workplaces were carried out and the most significant defects causing technical downtime were identified. The monitored values were recorded to the prescribed forms by operators and adjusters. The resulting analysis concentrated mainly on two main variables:

- total cumulative technical downtime at individual workplaces (Fig. 5),

- frequency of occurrence of failures in individual parts of workplaces (Fig. 6) [8].
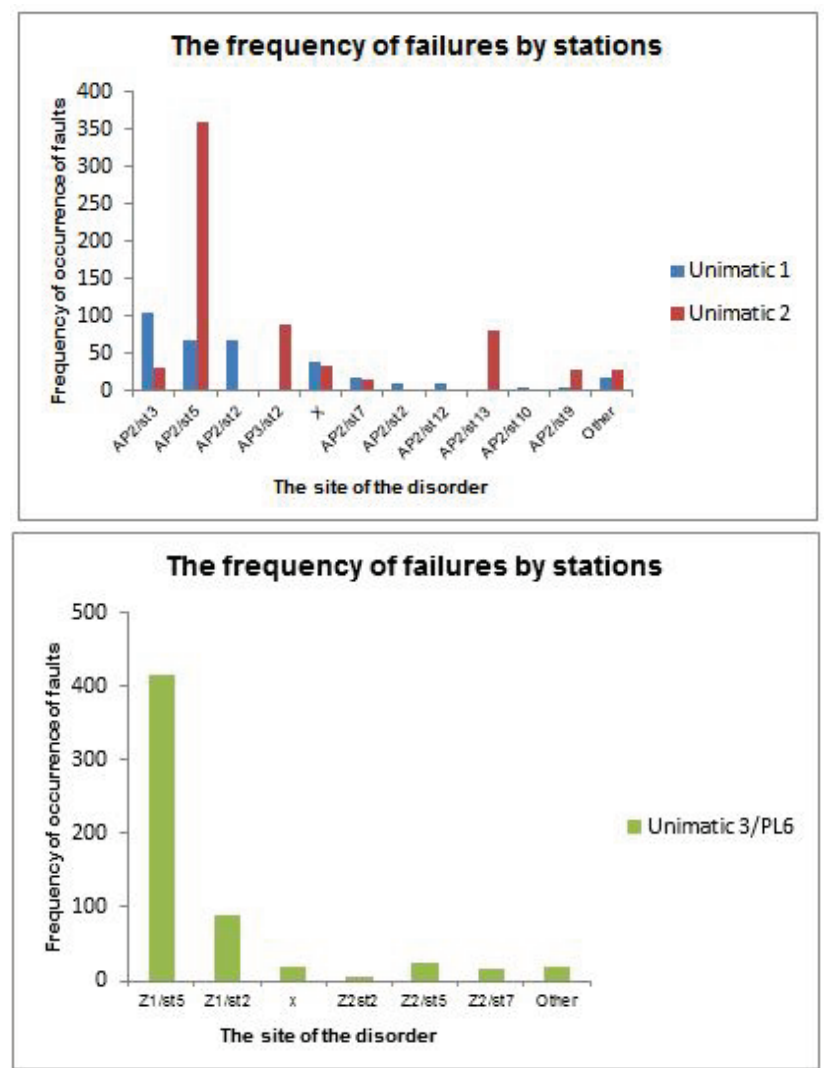

Figure 6 Paret analysis of the frequency of occurrence of failures for workplaces Unimatic 1, 2; Unimatic 3 / PL6

The results of the analysis were developed and used to design the solutions of critical problems at a particular workplace and served as key points in the preparation of the TPM's own implementation. Workplaces that are essential from the point of view of technical downtime have been identified.

\subsection{TPM Implementation Design at the Rail Assembly Workplace}

The main objective of the TPM generally is to enable the company to achieve almost $100 \%$ usability of machinery and equipment in relation to need, which represents the perfect state of the production process and manufacturing devices, where there are no failures, defective products and no accidents. Achieving this goal is difficult and is likely to be a long-term issue. 
The long-term objective in this case was to save maintenance costs and increase process productivity and stability, to increase OEE and improve quality and to reduce the cost of disposal of defective pieces at the assembly site. Therefore, for the initial implementation as well as for the further development of TPMs in the company, it is necessary to choose partial short-term objectives which are achievable and measurable in a shorter time horizon, mainly to keep the motivation of the employees involved. A partial goal was to reduce the value of downtime at the assembly workplace by up to $40 \%$. From the technical downtime values, the bases of technical downtime were set and the objectives of the technical downtime values for individual workplaces were determined (Fig. 7) [8].

\begin{tabular}{|l|c|c|}
\hline \multicolumn{1}{|c|}{ Workplace } & $\begin{array}{c}\text { Base of technical } \\
\text { downtime [hour/month] }\end{array}$ & $\begin{array}{c}\text { Objective of technical } \\
\text { downtime } \\
\text { [hour/month] }\end{array}$ \\
\hline Unimatic 1 & 71 & 42,6 \\
\hline Unimatic 2 & 52,5 & 31,5 \\
\hline Unimatic 3/PL6 & 93,8 & 56,3 \\
\hline
\end{tabular}

Figure 7 Target values of technical downtime based on technical downtime bases

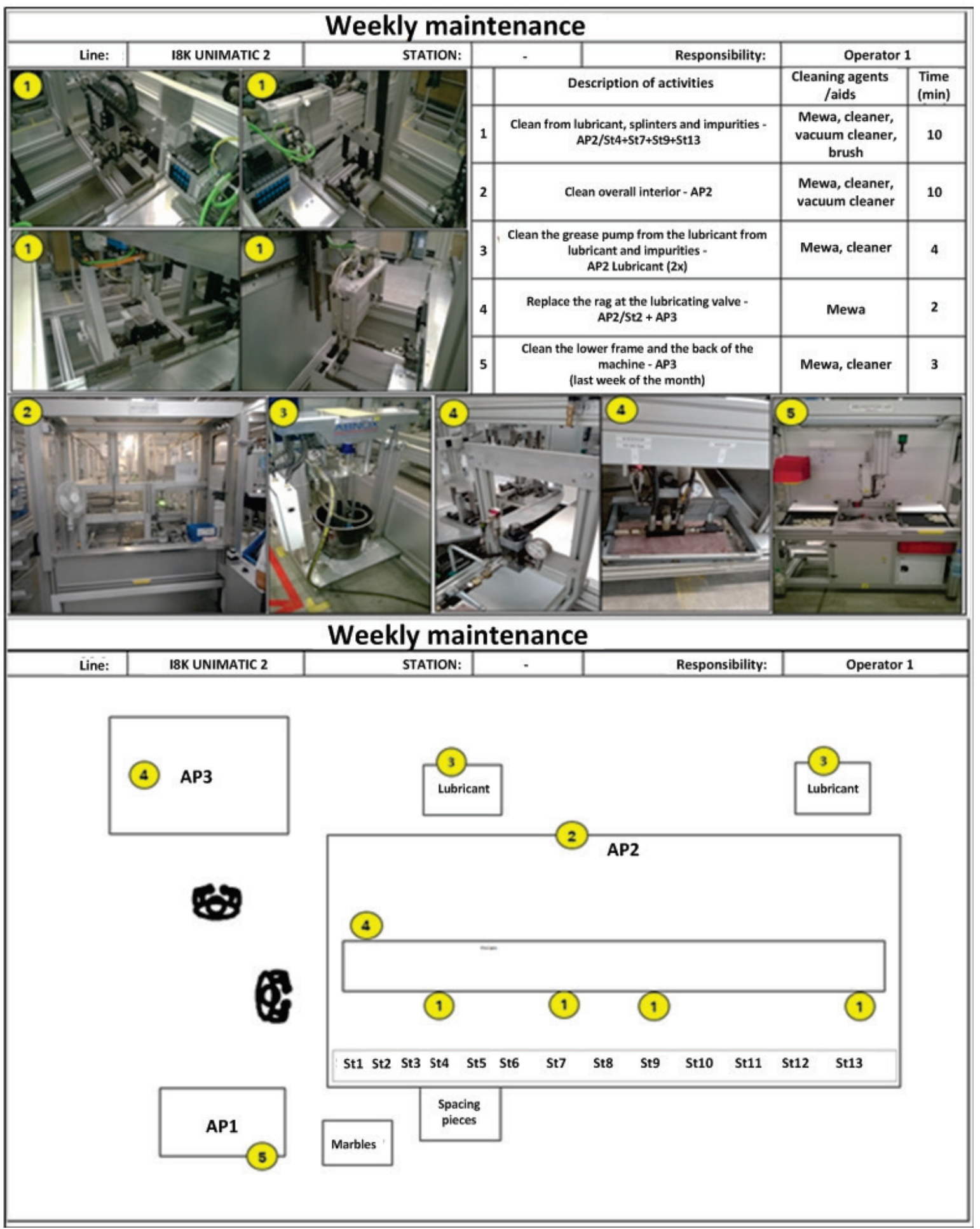

Figure 8 An example of the new weekly maintenance plans for operator 1 at the Unimatic 2 assembly workplace 


\subsection{TPM Implementation Phase}

The implementation of the TPM has its own phases. Successful completion of particular steps after each of these phases allows forward movement. The TPM implementation key points are:

- kick-off,

- TPM workshops,

- autonomous maintenance settings,

- TPM device cards and abnormal control,

- education and training.

The first step in kick-off was to start monitoring of technical downtime values on a weekly basis at selected workplaces. A significant step of the implementation was to determine the action plans which included TPM workshops necessary for the clarification of the basic TPM principles to all workers involved. The objective of these
TPM workshops was to put the workplaces in perfectly clean and optimal condition because most of the problems were caused by impurities which occur in the interior of the device. These impurities are formed during the assembly process mainly in the form of splinters from the spacing pieces and grease residues from rails lubrication.

The outputs from TPM workshops were used to the revision and creation of new maintenance standards which have also been self-sustaining to the necessary extent. New shift and weekly maintenance plans were designed in a well arranged and user-friendly way for the use of operators (Fig. 8), with focus on the visualization of all required maintenance and cleaning points.

Plans were designed to allow operators to perform as many tasks as possible, and adjusters could then concentrate on more specialized tasks.

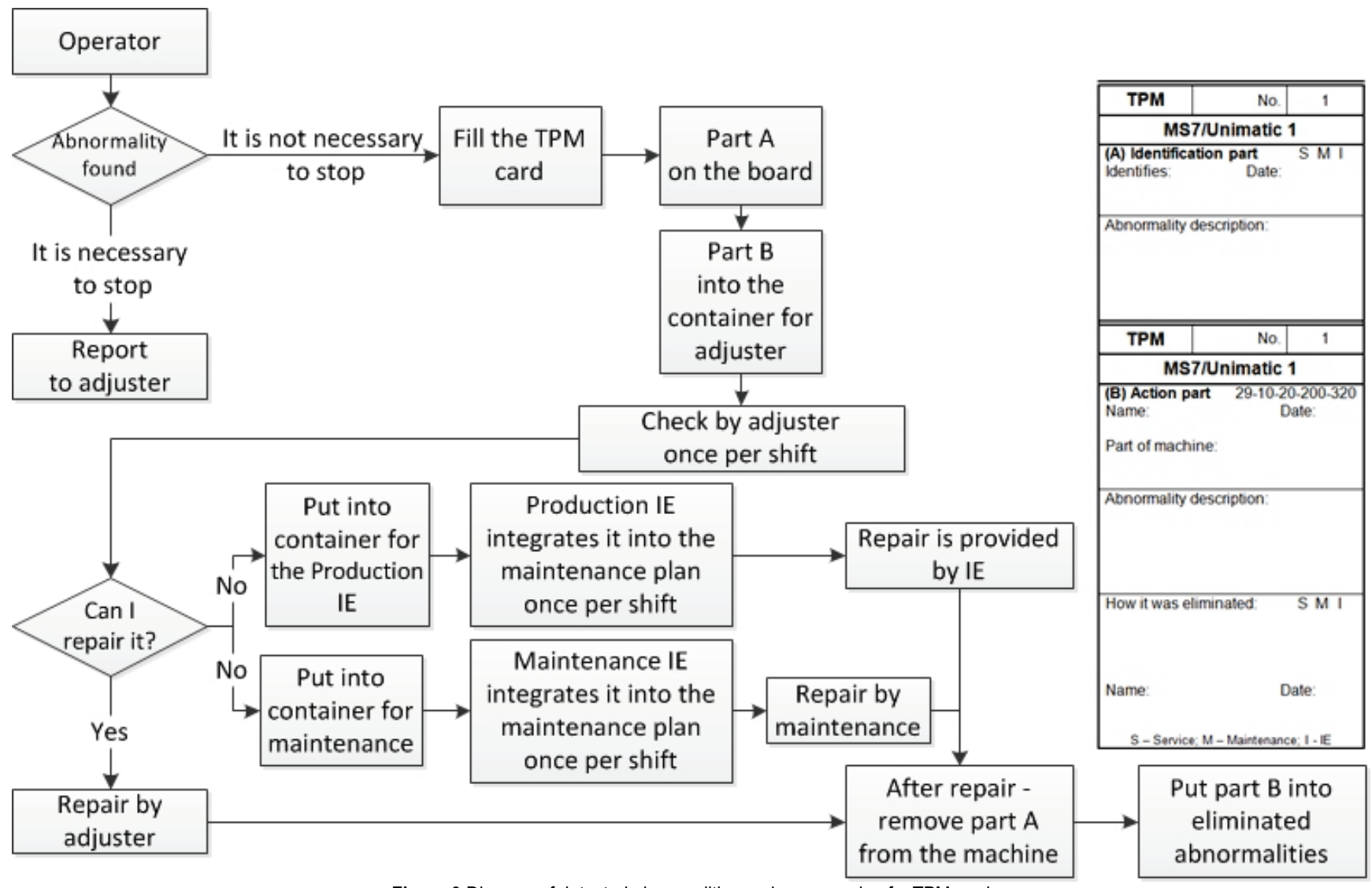

Figure 9 Diagram of detected abnormalities and an example of a TPM card

In the context of maintenance, great emphasis is placed on the control and early recognition of risks which can be revealed by using an efficient and active maintenance approach based on the principle of autonomous maintenance. For the purpose of early detection and documentation of abnormalities at the workplace which cause malfunctions and, in the extreme case, system shutdowns or device damage, a TPM cards system with a specific information transmission structure was designed within the TPM implementation at the assembly workplace (Fig. 9) [8].

By archiving the defects removed, the TPM cards system will be used as database of abnormalities which can be further analysed or tracked in the future.
The final point of the TPM implementation at the assembly workplace was the education and training of workers within the workshops, including the practical application of the TPM principles.

\subsection{Evaluation of the Progress of the TPM Implementation}

The implementation of the TPM at the assembly workplaces took place according to the action plan. From the point of view of meeting the set objectives, the reduction of technical downtime was precisely the activity which created the greatest effect on the development of technical downtime. The goal was achieved at the Unimatic 1 workplace and the other devices approached 
the given values at the time of implementation of the TPM principles (Fig. 10).

The main benefits of the TPM implementation at selected workplaces:

- technical downtime reduction,

- improving staff morale, but also their awareness of effective use of maintenance,

- improving processes leading to the maintenance of competitiveness and prosperity in the future,
- direct implementation of all principles and improvement actions on the new Unimatic 4 device, ensuring that the perfect condition of the device is maintained from the very beginning when the device was delivered,

- $\quad$ knowledge and experience from the implementation of TPM principles and especially the application of autonomous maintenance principles, which can also be used in other devices [8].
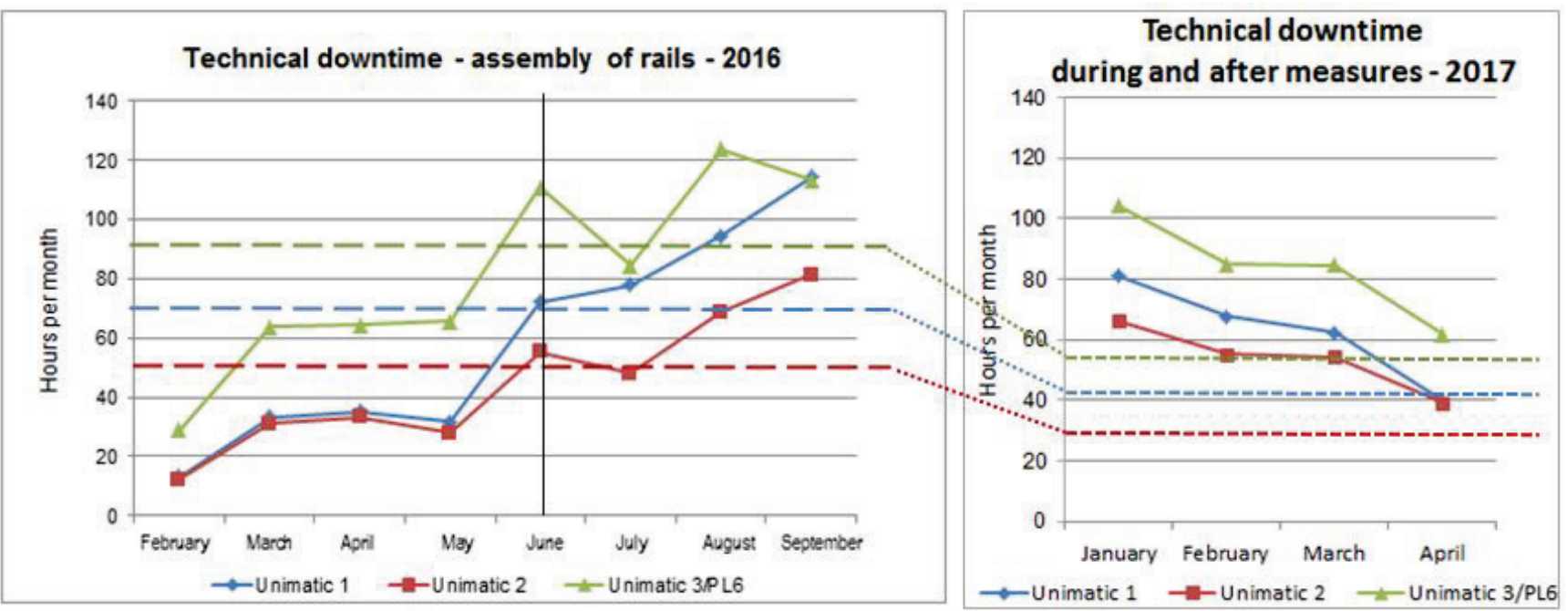

Figure 10 Comparison of technical downtime before and after the TPM implementation

\section{CONCLUSIONS}

This experimental study is focused on the implementation of the TPM elements in the field of maintenance in a selected engineering company. The basic key areas and their evaluation can be summarized as follows:

- An analysis of the technical downtime and unplanned shutdowns of production facilities due to failures, unplanned repairs and maintenance for the period between February and September 2016 was carried out (see Fig. 4).

- The results of the analysis showed that the greatest technical downtime occurred at the Unimatic 3/P L6 and Unimatic 1 workplaces. Based on these results, detailed monitoring and data collecting at individual workplaces were carried out and the most significant defects causing technical downtime were identified. The resulting analysis concentrated mainly on two main variables - total cumulative technical downtime at individual workplaces (Fig. 5) and frequency of occurrence of failures in individual sections of the workplaces (Fig. 6).

- The long-term objective in this case was to save the maintenance costs and increase the process productivity and stability, to increase OEE and improve quality and to reduce the costs of disposal of defective pieces at the assembly site. A partial goal was to reduce the value of downtime at the assembly workplace by up to $40 \%$. Based on the technical downtime values, the bases of technical downtime were set and the objectives of the technical downtime values for individual workplaces were determined (Fig. 7).
- New shift and weekly maintenance plans were designed in a well arranged and user-friendly way to be used by operators (Fig. 8).

- For the purpose of early detection and documentation of abnormalities at a workplace which cause malfunctions and, in extreme case, system shutdowns or device damage, a TPM cards system with a specific information transmission structure was designed within the TPM implementation at the assembly workplace (Fig. 9).

- The main benefits of the TPM implementation at selected workplaces are (see Fig. 10), technical downtime reduction, improving staff morale, but also their awareness of effective maintenance use, improving processes leading to the maintenance of competitiveness and prosperity in the future.

Direct implementation of all principles and improvement actions on the new Unimatic 4 device enabled to maintain the perfect condition of the device from the very beginning when it was delivered. The results of the experimental study showed that the amount of technical downtime was decreasing in all monitored devices in the monitored period, in one device up to the required goal of $40 \%$ already during the implementation time, in the other two during a few months. The knowledge and experience of implementing TPM principles, and in particular the application of autonomous maintenance principles in the company, confirm that the same principles can be applied to different devices.

Experimental verification of the implementation of TPM principles in the company has confirmed both the topicality of the solved issues and the possibility of using these principles in the specific area of maintenance of assembly workplaces in various industrial organizations. 


\section{REFERENCES}

[1] Bevilacqua, M. \& Braglia, M. (2000). The analytic hierarchy process app lied to maintenance strategy selection. Reliability Engineering \& System Safety, 70(1), 71-83. https://doi.org/10. 1016/S0951-8320(00)00047-8

[2] Cierna, H. \& Sujova, E. (2016). Application of modern QMS - Kaizen management system. Modern Machinery (MM) Science Journal, November 2016, 1456-1464. https://doi.org/10.17973/ MMSJ.2016_11_2016162

[3] Heizer, J. H. \& Render, B. (2011). Principles of Operations Management. New Yersey, N. J.: Prentice Hall.

[4] Higgins, L. R., Brautigam, D. P., \& Mobley, R. K. (2014). Maintenance Engineering Handbook. New York, NY: McGraw-Hill.

[5] Legát, V., et al. (2013). Management and Maintenance Engineering (in Czech) Př́ibram: Pofessional Publishing.

[6] Markulik, S. \& Kozel, R. (2016). Transformation of product characteristics in terms of a management system. Modern Machinary (MM) Science Journal, 900-902. https://doi.org/10.17973/MMSJ.2016_06_201607

[7] Méndez, J. D. M. \& Rodriguez, R. S. (2017). Total productive maintenance (TPM) as a tool for improving productivity: a case study of application in the bottleneck of an auto-parts machining line. The International Journal of Advanced Manufacturing Technology, 92(1-4), 1013-1026. https://doi.org/10.1007/s00170-017-0052-4

[8] Michalčík, V. (2017). Implementation of TPM in selected workplaces (in Czech). Ostrava, Retrieved from https://dspace.vsb.cz/handle/10084/117435

[9] Nakajima, S. (1988). Introduction to TPM. Productivity USA, Press, Inc. Cambridge.

[10] Nečas, L. (2016, May). The effectiveness of the implementation of new management systems in maintenance for metallurgical production. $25^{\text {th }}$ International Conference on Metallurgy and Materials: conference, METAL 2016, Ostrava, Czech Republic.

[11] Negrao, L. L. L., Godinho, F. M., \& Marodin, G. (2017). Lean practices and their effect on performance: a literature review. Production Planning \& Control, 28(1), 33-56. https://doi.org/10.1080/09537287.2016.1231853

[12] Rodrigues, M. \& Hatakeyama, K. (2006). Analysis of the Fall of TPM in Companies. Journal of Materials Processing Technology, 179(1-3), 276-279. https://doi.org/10.1016/j.jmatprotec.2006.03.102

[13] Schindlerová, V., Šajdlerová, I., \& Zmeškal, P. (2006). Implementation of the Principles of TPM in Field of Maintenance Preparations. Transactions of the VŠB Technical University of Ostrava, Mechanical Series, 62(1), 51-57. https://doi.org/10.22223/tr.2016-1/2010

[14] Sekine, K. \& Arai, K. (1998). TPM for the lean factory: innovative methods and worksheets for equipment management. Portland, Or.: Productivity Press

[15] Stadnicka, D. \& Ratnayake, R. M. Ch. (2017). Enhancing Aircraft Maintenance Services: A VSM Based Case Study. Procedia Engineering, 182, 665-672. https://doi.org /10.1016/j.proeng.2017.03.177

[16] Turečková, K. (2015). Sectoral industrial agglomeration and network externalities: conceptof ICT sector. $5^{\text {th }}$ International Conference on Applied Social Science. USA: IERI, 50-55.

[17] Sadilek, M., Cep, R., Sadilkova, Z., Valicek, J., \& Petrkovska, L. (2013). Increasing Tool Life during Turning with a Variable Depth of Cut. Materiali in Tehnologije, 47(2), 199-203.

[18] Legutko, S. (2009). Development trends in machines operation maintenance. Eksploatacja $i$ NiezawodnoscMaintenance and Reliability, 2, 8-16.

[19] Krolczyk, G., Legutko, S., \& Stoic, A., (2013). Influence of cutting parameters and conditions onto surface hardness of duplex stainless steel after turning process. Tehnicki vjesnikTechnical Gazette, 6, 1077-1080.

[20] Jasiulewicz-Kaczmarek, M. \& Saniuk, A. (2018). How to make maintenance processes more efficient using lean tools? Advances in Social and Occupational Ergonomics: Proceedings of the AHFE 2017 Conference on Social and Occupational Ergonomics, July 17-21, 2017, Los Angeles, California, USA Series: Advances in Intelligent Systems and Computing, 605, 9 -20.

[21] Jasiulewicz-Kaczmarek， M. \& Żywica， P. (2018). The concept of maintenance sustainability performance assessment by integrating balanced scorecard with nonadditive fuzzy integral. Eksploatacja I Niezawodnosc Maintenance and Reliability, 20(4), 650-661.

[22] Jasiulewicz-Kaczmarek，M. (2016). SWOT analysis for Planned Maintenance strategy - a case study, in: Alexandre Dolgui, Robert Grubbström, Dmitry Ivanov and Farouk Yalaoui (Eds.). IFAC Conference on Manufacturing Modelling, Management and Control, France, MIM 2016 Troyes, France, 28-30 June 2016, IFAC - Papers On Line, 49(12), 674-679. https://doi.org/10.1016/j.ifacol.2016.07.788

[23] Petrovic, S., Milosavljevic, P., \& Lozanovic Sajic, J. (2018). Rapid Evaluation of Maintenance Process Using Statistical Process Control and Simulation. International Journal of Simulation Modelling, 17(1), 119-132. https://doi.org/10.2507/IJSIMM17(1)424

[24] Sadeghpour, H., Tavakoli, A., Kazemi, M., \& Pooya, A. (2019). A novel approximate dynamic programming approach for constrained equipment replacement problems: A case study. Advances in Production Engineering \& Management, 14(3), 355-366. https://doi.org/10.14743/apem2019.3.333

\section{Contact information}

Vladimíra SCHINDLEROVÁ, PhD, Eng.

(Corresponding author)

VŠB-Technical University of Ostrava,

Faculty of Mechanical Engineering,

Department of Mechanical Technology,

17. listopadu 15, 709 33, Ostrava, Czech Republic

E-mail: vladimira.schindlerova@vsb.cz

Ivana ŠAJDLEROVÁ, PhD, Eng.

VŠB-Technical University of Ostrava,

Faculty of Mechanical Engineering,

Department of Mechanical Technology,

17. listopadu 15, 709 33, Ostrava, Czech Republic

E-mail: ivana.sajdlerova@vsb.cz

Václav MICHALČíK, Eng.

VŠB-Technical University of Ostrava

Faculty of Mechanical Engineering,

Department of Mechanical Technology,

17. listopadu 15, 709 33, Ostrava, Czech Republic

E-mail: vaclav.michalcik@vsb.cz

Jan NEVIMA, doc, PhD, Eng.

VŠB-Technical University of Ostrava,

Faculty of Mechanical Engineering,

Department of Mechanical Technology,

17. listopadu 15, 709 33, Ostrava, Czech Republic

E-mail: jan.nevima@vsb.cz

\section{Lucie KREJČí, PhD, Eng}

VŠB-Technical University of Ostrava,

Faculty of Mechanical Engineering,

Department of Mechanical Technology,

17. listopadu 15, 709 33, Ostrava, Czech Republic

E-mail: lucie.krejci@vsb.cz 